\title{
ARM Based Smart Energy Metering with Digital Anti-Stealing Techniques
}

\author{
Tojo M Thomas ${ }^{1}$, Jinu Isaac Kuruvilla ${ }^{2}$, Gopakumar M G \\ M-Tech (VLSI and Embedded System), Dept of ECE, Mangalam College of Engineering Kottayam, Kerala, India ${ }^{1}$ \\ Assistant Professor, Department of ECE, Mangalam College of Engineering Kottayam, Kerala, India ${ }^{2,3}$
}

\begin{abstract}
Now-a-days technology has developed to a large extend. At the same time the need for systems with automation and high security are preferred. Electricity-stealing is a universal problem for all power utilities, causing a large amount of economic losses. Therefore, there is an increasing need of intelligent anti-stealing technologies for the power utilities to rapidly detect the electricity-stealing suspects. Traditional meter reading for electricity consumption and billing is done by human operator from houses to houses and building to building. This requires huge number of labour operators and long working hour to achieve complete area reading and billing. By adapting this paper we can avoid such problems.
\end{abstract}

Keywords: Anti-stealing, Smart Metering, ARM Cortex M, STM32F0Discovery.

\section{INTRODUCTION}

Electricity is one of the most important blessings that science has given to mankind. It has also become a part of modern life. Electricity has many uses in our day to day life. Electricity theft can be in the form of fraud (meter tampering), stealing (illegal connections), billing irregularities, and unpaid bills. Now-a-days technology has developed to a large extend. At the same time the need for systems with automation and high security are preferred. Therefore, there is an increasing need of intelligent anti-stealing technologies for the power utilities to rapidly detect the electricity-stealing suspects.

Ignorance is a main reason of wastage of electricity. So understanding or regular reminding helps to reduce the wastage. In the paper first focus is given to the antistealing techniques. This is achieved through different ways. First of all let us know the normal stealing definitions. Unauthorized use of electricity and theft of electricity are two terms used for the stealing of electricity. Basically stealing is done due to the inefficiency of the energy meter. The poor sealing of energy meter can easily be removed and it may not be noticeable. Thus through meter malfunctioning one can steal the electricity.

First of all the energy meter is planned to enclose with a digital secure system. Authorized person only can access it. Otherwise a message will be sent to the authority regarding the unauthorized access. Unusual usage can be determined and it may be informed to the authorities. Second focus is to the meter reading methodology. As mentioned earlier current system is not economical and proper. So we can use a transceiver unit and a real time clock (RTC) unit to transmit the usage every month. Thus the bill is reached to the consumer as message and for the authority it can be reached through transceiver.

The third focus is dealt with consumer notice board which contains many notifications and instructions to the consumer about the supply constraints. When the supply is running in over/lower voltage, notifies in the display. Peak time will be detected and notifies the consumer. If the daily usage considerably exceeds the average usage then a warning will be given. Consumer has the facility to check the instantaneous usage through text message. Overall it will helps the state economically and useful to the consumers with many attractive services. It will be reliable and accurate, which is made up of strong ARM Cortex M0 core based controller STM32F051R8T6.

\section{LITERATURE SURVEY}

When most people think of theft, the first things that come to mind are high profile robberies: diamonds, banks, and department store safes. Maybe if you were a bit of a techie, you'd think of digital theft involving music and movies over the internet. In reality, the most commonly stolen commodities in the US are identities, automobiles and electricity. That last one surprises most people, but the best estimates say that about $\$ 6$ billion in revenue is lost each year in the US from energy theft.

When someone alters their electricity supply without the authority of their supplier, they are meter tampering. This tamper prevents the device from recording the correct energy usage and therefore the meter is undercharged. Another common stealing topology by the business users are illegal connections. Allows electricity supplied to that person/organisation's supply point under a specific tariff to be used for a purpose other than as contemplated by that tariff. These are the common electricity stealing methods. Proper awareness about the usage of electricity among people can reduce the wastage. Ignorance is a main reason of wastage of electricity. So understanding or regular reminding helps to reduce the wastage. The present system of billing for electricity includes a tedious job of taking the reading from the meter of each consumer. For this the man who takes the reading has to go to each and every meter and take the reading manually. This is a very time consuming process and hence we may need more men to do this work and hence become costly. 
References [1] - [5] deal with both Anti Stealing and B. Smart Metering. But they did not consider user acknowledgment functions. They are dealing with the functionalities of their circumstance so it may not be suitable for our concern. References [6] - [7] deal with both some user acknowledgment functions and smart metering techniques. References [8] - [11] deal with different anti stealing methods used in varied environments. In each paper they introduce different aspects. References [12] - [14] deal with smart metering techniques developed in different locations.

\section{III.PROPOSED SYSTEM}

In our paper "ARM Based Smart Energy Metering With Digital Anti-Stealing Techniques" deals three different aspects. They are Anti-stealing techniques, User acknowledgment functions and Smart metering techniques.

\section{A. FUNCTIONS}

a. Anti-Stealing Techniques

The main two terms in stealing of electricity are tampering of meter and illegal connection. In the proposed system these two cases were considered. Tampering of meter is restricted with giving access only to the authorized persons to the meter with a digital security. Any attempt to break this condition will be notified to the authority. Illegal connections refers to the electricity supplied to that person/organisation's supply point under a specific tariff to be used for a purpose other than as contemplated by that tariff. In this case a particular load value would be given to each customer thus by monitoring their usage can be used to notify the authority.

\section{b. User Acknowledgements}

Proper awareness about the usage of electricity can reduce the wastage. Ignorance is a main reason of wastage of electricity. So understanding or regular reminding helps to reduce the wastage. Thus in our proposed system different user acknowledgement schemes were considered. They are peak time/low voltage notification, over usage notification, real time usage and user initiated usage counter. The unawareness or ignorance of low voltage or peak time will affect our valuable electric equipment's. So in the proposed system when the line voltage decreases to a limit its notification will be generated. User initiated usage counter counts the usage after an initiation has given by the user. Thus we can check the usage between any instants.

\section{c. Smart Metering}

The present system of billing for electricity includes a tedious job of taking the reading from the meter of each consumer. For this the man who takes the reading has to go to each and every meter and take the reading manually. This is a very time consuming process and hence we may need more men to do this work and hence become costly. In the proposed system a transmitter unit present which will transmit the usage to the electricity board and notification to the customer in every month automatically.

\section{STM32F0 DISCOVERY}

The core part in our paper is the STM32F0DISCOVERY board. It is an ARM based development board which includes an STLINK/V2 embedded debug tool interface.

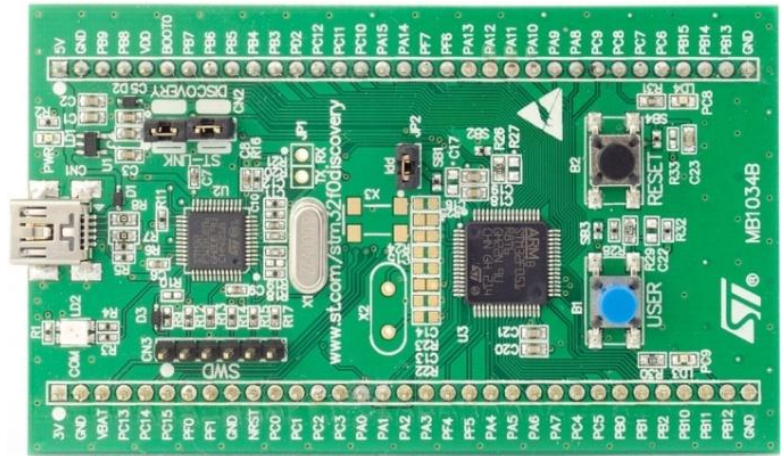

Fig 3.1 STM32F0 Discovery [19]

\section{a. Features}

STM32F051R8T6 microcontroller featuring 64 KB Flash memory, 8 KB RAM in an LQFP64 package

On-board ST-LINK/V2 with selection mode switch to use the kit as a standalone STLINK/ V2 (with SWD connector for programming and debugging)

Board power supply: Through USB bus or from an external $5 \mathrm{~V}$ supply voltage

External application power supply: $3 \mathrm{~V}$ and $5 \mathrm{~V}$

Four LEDs

Two push buttons (user and reset)

b. STM32F051R8T6Microcontroller

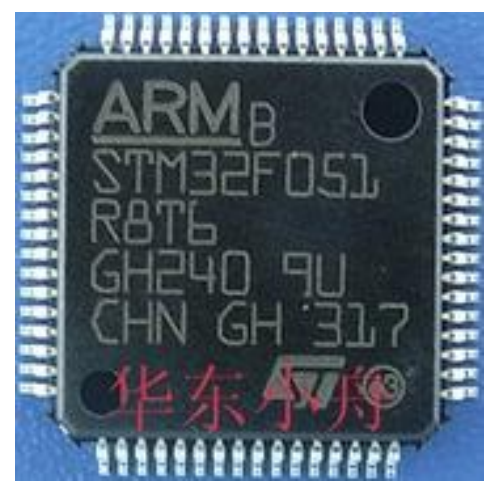

Fig 3.2 STM32F051R8T6 Package [19]

Operating conditions:

- Voltage range: $2.0 \mathrm{~V}$ to $3.6 \mathrm{~V}$ ARM 32-bit Cortex ${ }^{\circledR}-\mathrm{M} 0$ CPU (48 MHz max) Memories

- 16 to 64 Kbytes of Flash memory

- 8 Kbytes of SRAM with HW parity checking Clock management

- 4 to $32 \mathrm{MHz}$ crystal oscillator

- $32 \mathrm{kHz}$ oscillator for RTC with calibration

- Internal $8 \mathrm{MHz}$ RC with x6 PLL option

- Internal $40 \mathrm{kHz}$ RC oscillator

Calendar RTC with alarm and periodic wakeup from Stop/Standby

Power-on/Power down reset (POR/PDR)

$1 \times 12$-bit, $1.0 \mu \mathrm{s}$ ADC (up to 16 channels) 
- Conversion range: 0 to $3.6 \mathrm{~V}$

- Separate analog supply from 2.4 up to 3.6 One 12-bit D/A converter Up to 55 fast I/Os

- All mappable on external interrupt vectors

- Up to $36 \mathrm{I} / \mathrm{Os}$ with $5 \mathrm{~V}$ tolerant capability Serial wire debugs (SWD) Up to 11 timers Communication interfaces

- Up to two I2C interfaces; one supporting Fast Mode Plus (1 Mbit/s) with $20 \mathrm{~mA}$ current sink, SMBus/PMBus, and wakeup from STOP

- Up to two USARTs supporting master synchronous SPI and modem control; one with ISO7816 interface, LIN, IrDA capability, auto baud rate detection and wakeup feature

- Up to two SPIs (18 Mbit/s) with 4 to 16 programmable bit frame, 1 with I2S interface multiplexed

c. $\quad$ Embedded ST-LINK/V2

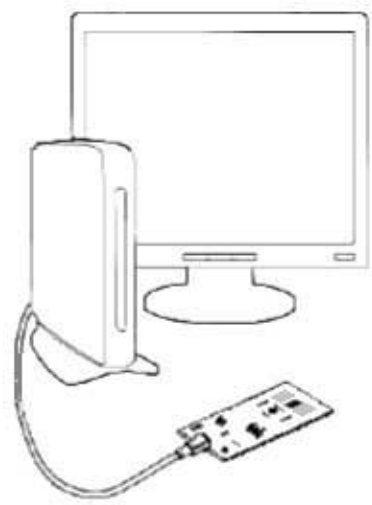

Fig 3.3 Typical configuration [19]

The ST-LINK/V2 programming and debugging tool is integrated on the STM32F4DISCOVERY. The embedded ST-LINK/V2 can be used in 2 different ways according to the jumper states

- Program/debug the MCU on board,

- Program/debug an MCU in an external application board using a cable connected to SWD connector CN2.

The embedded ST-LINK/V2 supports only SWD for STM32 devices.

\section{IV.BLOCK DIAGRAM AND WORKING}

A.

BLOCK SCHEMATIC

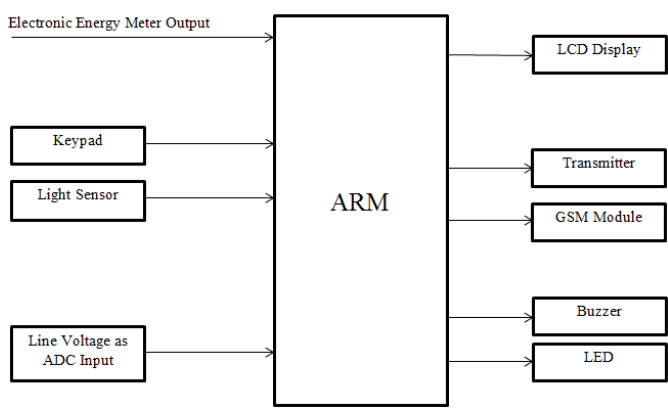

Fig 4.1 Block Diagram a. Electronic Energy Meter

Electronic Energy Meter is based on Digital Micro Technology (DMT) and uses no moving parts. So the EEM is known as "Static Energy Meter" In EEM the accurate functioning is controlled by a specially designed IC called ASIC (Application Specified Integrated Circuit). ASIC is constructed only for specific applications using Embedded System Technology. Similar ASIC are now used in Washing Machines, Air Conditioners, Automobiles, Digital Camera etc.

In addition to ASIC, analogue circuits, Voltage transformer, Current transformer etc. are also present in EEM to "Sample" current and voltage. The 'Input Data' (Voltage) is compared with a programmed "Reference Data' (Voltage) and finally a 'Voltage Rate' will be given to the output. This output is then converted into 'Digital Data' by the AD Converters (Analogue- Digital converter) present in the ASIC.

The Digital Data is then converted into an "Average Value". Average Value / Mean Value are the measuring unit of power. The output of ASIC is available as "Pulses" indicated by the LED (Light Emitting Diode) placed on the front panel of EEM. These pulses are equal to Average Kilo Watt Hour (kWh / unit). Different ASIC with various $\mathrm{kWh}$ are used in different makes of EEMs. But usually 800 to 3600 pulses / $\mathrm{kWh}$ generating ASIC s are used in EEMs. The output of ASIC is sufficient to drive a Stepper Motor to give display through the rotation of digits embossed wheels. The output pulses are indicated through LED. The ASIC are manufactured by Analogue Device Company. ADE 7757 IC is generally used in many countries to make EEMs. ADE 7555 / 7755 ASIC maintains the international standard CLASS I IEC 687/ 1036.

In the paper we are replacing EEM with a pulse generator. Pulse generation is carried out by an astable multi vibrator.

\section{ASTABLE MULTIVIBRATOR}

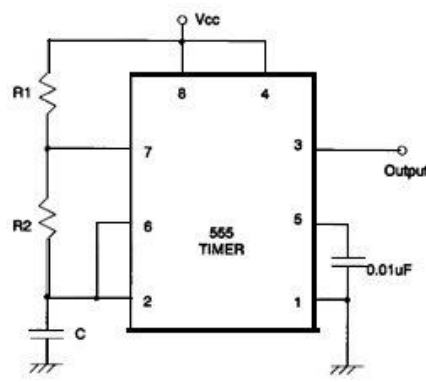

Fig 4.2 Astable Multivibrator Using 555 Timers $\mathrm{t} 1=0.693(\mathrm{R} 1+\mathrm{R} 2) \mathrm{C} 1$ $\mathrm{t} 2=0.693(\mathrm{R} 2) \mathrm{C} 1$

b. Keypad

A keypad is a set of buttons arranged in a block or "pad" which usually bear digits, symbols and usually a complete set of alphabetical letters. If it mostly contains numbers then it can also be called a numeric keypad. Keypads are found on many alphanumeric keyboards and on other devices such as calculators, push-button telephones, combination locks, and digital door locks, which require mainly numeric input. 
In the project keypad is used as an input device which can be used as security lock for the energy meter.

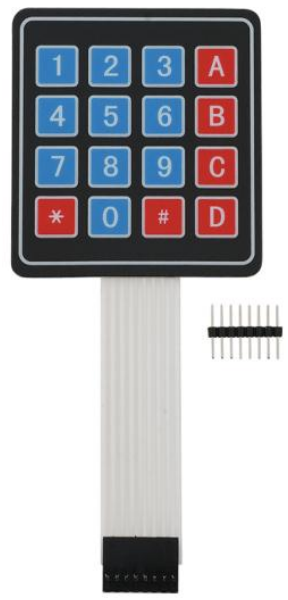

Fig 4.3 Keypad [18]

\section{c. Light Sensor}

Light sensor is also used here for the security purpose.

\section{d. Line Voltage as ADC Input}

ADC input is the input supply voltage which is used for the calculation of over voltage and peak time analysis.

e.

LCD Display

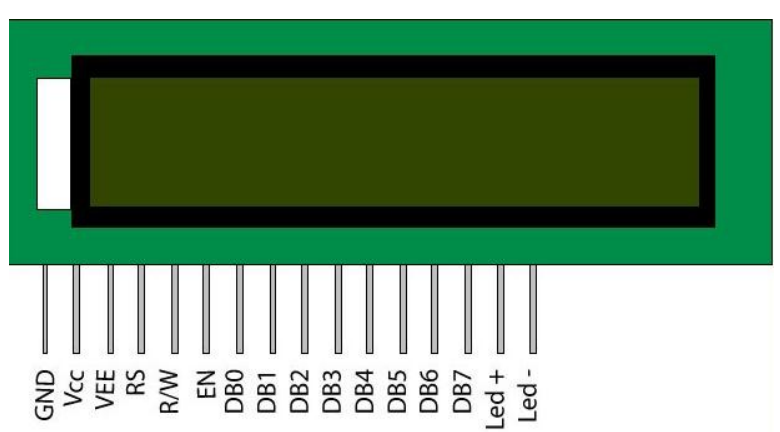

Fig 4.4 LCD Display [18]

A 16x2 LCD display is very basic module and is very commonly used in various devices and circuits. These modules are preferred over seven segments and other multi segment LEDs. The reasons being: LCDs are economical; easily programmable; have no limitation of displaying special \& even custom characters (unlike in seven segments), animations and so on.

A $16 \times 2$ LCD means it can display 16 characters per line and there are 2 such lines. In this LCD each character is displayed in $5 \times 7$ pixel matrix. This LCD has two registers, namely, Command and Data. The command register stores the command instructions given to the LCD. A command is an instruction given to LCD to do a predefined task like initializing it, clearing its screen, setting the cursor position, controlling display etc. The data register stores the data to be displayed on the LCD. The data is the ASCII value of the character to be displayed on the LCD.

\section{f. Transmitter (Bluetooth Device)}

Core Modules using HC-06 main modules, leads from the module interface including VCC, GND, TXD, and RXD.
Reserve LED output pin status, Single Chip Microcomputer can be judged connected or not by the foot state, KEY pin is invalid for slave. LED indicate show connection status, when it is flashing means nonconnection, normally on mean it connect successfully Backplane set anti-reverse diode with $3.3 \mathrm{~V}$ LDO, input voltage: $3.6-6 \mathrm{~V}$, Unpaired current: about $30 \mathrm{MA}$, Paired: about $10 \mathrm{MA}$, input voltage can't exceed 7V Interface level $3.3 \mathrm{~V}$, can be directly connected the various SCM (51, AVR, PIC, ARM, MSP430, etc.), the microcontroller can also be directly connected without MAX232 Effective distance : 10M After repaired, can used as full-duplex serial, supports 8 data bits, 1 stop bit, no parity communication format.

\section{g. GSM Module}

A GSM modem is a specialized type of modem which accepts a SIM card, and operates over a subscription to a mobile operator, just like a mobile phone. From the mobile operator perspective, a GSM modem looks just like a mobile phone.

When a GSM modem is connected to a computer, this allows the computer to use the GSM modem to communicate over the mobile network. While these GSM modems are most frequently used to provide mobile internet connectivity, many of them can also be used for sending and receiving SMS and MMS messages.

\section{B. OPERATIONS}

The energy meter output is given to the controller and it is consider as an input for the controller. A counter is working on the basis of this input. Monthly, daily, hourly and user counters run on the basis of this input if the corresponding conditions were satisfied. Monthly counter transmits its value at the end of every month and resets its value. Daily counter is used for monitoring the average use. If the daily usage exceeds average notification will be shown and an indicating LED also will be turned on. The hourly counter is used for monitoring the over usage. If the usage found high message will sent to the authority. User counter is used to measure the instantaneous usage controlled by the user.

The anti-stealing techniques are carried out in different ways. The energy meter is the property of state board so consumer need not get the access of it. So it can be operatable only to the authorized persons by providing a secured lock system. If the lock get unauthorised access or malfunctions message regarding the same will sent to the authority. The main stealing is done through overload connecting. Now a day's individual raid only can detect it. But it is not practical. So by proper calculations and programming in the controller can detect the stealing and it can be noticed to the authorities by different methods. This is done with the help of the hour counter. Smart metering can be achieved with a transmitter unit.

Thus meter reading becomes automated. Smart meter reading is done with reference of RTC. Thus during every month metering happens automatically. There are lot of consumer services with the help of LCD and GSM module. Low voltage/peak time is achieved through ADC in the board. 
When the condition is met a buzzer will be turned on and A. notification displays on LCD.

\section{IDES AND SOFTWARE'S USED}

\section{A. IAR EMBEDDED WORKBENCH}

IAR Embedded Workbench provides an integrated development environment that allows us to develop and manage complete application projects for embedded systems. The environment comprises tools for compiling, linking, and debugging with comprehensive and specific target support. We will have the same user interface regardless of which microcontroller you use.

Third-Party Tools and Utilities

There is a wide range of third-party tools and utilities that can be integrated with IAR Embedded Workbench. Examples of such products are version control systems, editors, C-SPY plugin modules for RTOS-aware debugging and different debug probes, protocol stacks, etc.

Interoperability with Other Build Tools

Depending on which object format and which application binary interfaces your products use, the IAR tool chain can be interoperable with tool chains from other vendors. The level of interoperability ranges from debugging an IAR tools executable file in a third-party debugger to full linklevel compatibility.

\section{B. ATOLLICTRUESTUDIO}

AtollicTrueSTUDIO is a $\mathrm{C} / \mathrm{C}++$ compiler and debugger development suite for ARM microcontrollers that will help to improve our software quality. By utilizing the capabilities of TrueSTUDIO we can eliminate many of the problems software engineers are meeting today, and focus our time and energy on what really matters - developing high quality embedded software. AtollicTrueSTUDIO provides unique features for improving our software quality, including features for software engineering, team collaboration and software testing.

\section{ECLIPSE}

Eclipse can be used as a $\mathrm{C} / \mathrm{C}++$ compiler and debugger development suite for ARM microcontrollers that will help to improve our software quality. It is free software so we can use it in any extent.

\section{EAGLE}

EAGLE (Easily Applicable Graphical Layout Editor) by Cad Soft Computer is a flexible, expandable and scriptable EDA application with schematic capture editor, PCB layout editor, auto-router and CAM and BOM tools developed by Cad Soft Computer $\mathrm{GmbH}$, Germany, since 1988. EAGLE is popular among smaller design houses and in academia for its favourable licensing terms and rich availability of component libraries on the web. PCB design is carried out with this software.

\section{EXPERIMENTAL RESULTS}

The board features were tested in different conditions. GPIO, Interrupt, UART, ADC, Systick Timer were tested for the paper itself.

\section{MODULE TESTING}

\section{a. GSM Module}

GSM module was tested using a sample code. In the testing phase we have sent different type text messages to different mobile operators with single sim inserted in the module.

\section{b. Bluetooth Module}

Bluetooth module was tested using a sample code. In the testing phase it is connected with different devices. Transmit different type text messages.

\section{c. LCD Module}

LCD module was tested with a sample code. In the testing time different conditions tested. Different texts in different ways were tested. Printing in different areas was also tested. Command write and data write were studied deeply.

\section{d. Buzzer, LED and Switch}

Buzzer, LED and Switch testing were done successfully.

\section{B. RESULT OBTAINED}

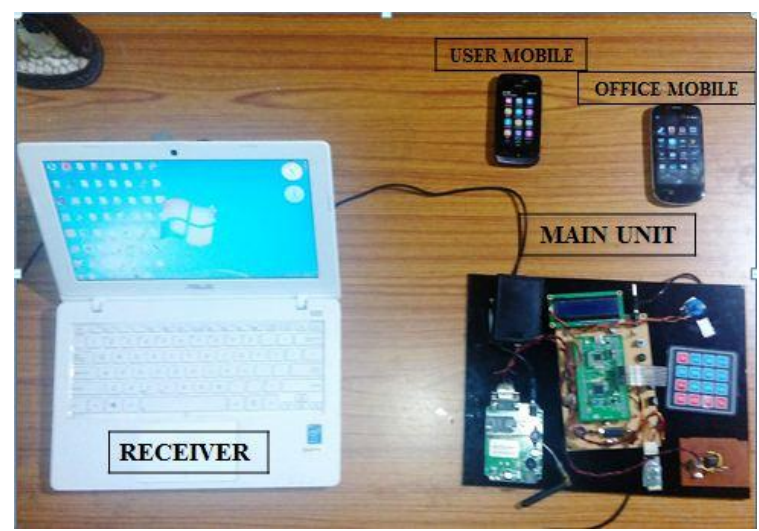

Fig 6.1 Hardware Implementation

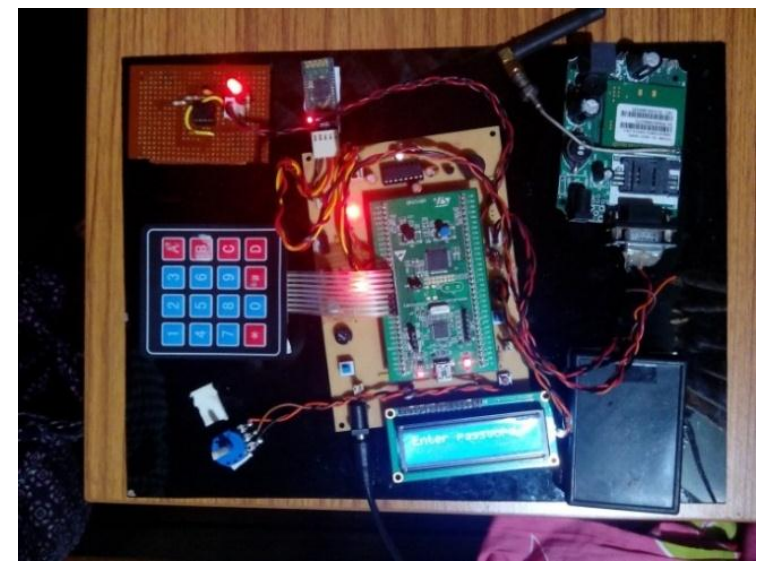

Fig 6.2 Main Unit

Hardware implemented and tested with appropriate code. Each and every module configuration is done and tested successfully.

GSM and Bluetooth are connected through UART. While keypad and LCD connected directly. ADC is configured to detect the input analog voltage.

Buzzer, LED and switch designed with PCB design. It is tested well with the circuit operation. 
Overall operation result obtained as follows, first up all switch on the device by connecting with the adapter then power LED and LCD display will be turned on LCD displays a default date and time to change the date and time press "*" in the keypad. Thus we can change the date and time. At all times with respect to the pulse input from the energy meter corresponding reading displays on the LCD display. A low voltage detects at the ADC input, buzzer will be turned on and notification displays on the LCD. If an authorised person wants to operate meter he has to press "\#" followed by the password. If the password typed wrong for more than three times it is taken as the unauthorized access and message will be sent to the authority.

Month change causes the month counter value to be sent to the electricity office and user mobile phone. If the usage exceeds the limit then message will be sent to the authority. If the usage exceeds average usage then a notification will be displayed in the LCD and an indicating LED will turned on.

User controlled usage counter starts when the consumer turns on the particular switch. At the time when the consumer turned off the switch detailed usage information will be sent to the user mobile phone.

Thus overall functions were tested and positive results were obtained.

\section{ADVANTAGES}

"ARM based smart energy metering with digital antistealing techniques" is a simple and useful project which is having much relevance in the current situations. It is based on a strong ARM Cortex M0 processor so it can be used to extent the features to an extreme extent. All the operations are user friendly to handle.

\section{DISADVANTAGES}

The input power has to be given at all times. The clock unit and counting function has to continue every time. So we need a continuous power supply to the system. Once the power lost all the data should be reset.

\section{IX.FUTURE SCOPE}

If the transmitter section is replaced with uploading the data to the internet server is an interesting scope of the paper. One camera interfacing with the security system will be more attractive. In this system, the information of electricity theft is directly reported to the central authority. Therefore, utilities can take immediate legal action against the accused consumer and hence control electricity theft to a great extent. The proposed meter is thus highly useful for power utilities for reducing electricity pilfering and ensuring revenue collection.

\section{CONCLUSION}

This paper presents an advanced metering infrastructure for distribution networks, which can defend electricitystealing from a large set of users via short-term load forecast instead of traditional on-site checking. By this, tracking the electricity-stealing suspects at distribution networks brings the emerging smart grid a labor-saving defense of electricity-stealing.

\section{ACKNOWLEDGMENT}

Iwould like to thank Mangalam College of Engineering for the chance toprepare the paper. I would also like to thank my friends for sharing their valuable experience for this paper.I would like to thank the HOD Prof. AshaPaniker and my staff advisor Ms. BinuManohar for their timely help and encouragement.Finally I would like to thank Mr. JinuIsaac Kuruvilla and Mr. Gopakumar M G, Asst. Professors, Electronics and Communication Engineering Department for their proper guidance and support.

\section{REFERENCES}

[1] Kunold, I.; Kuller, M.; Bauer, J. and Karaoglan, N., "A system concept of an energy information system in flats using wireless technologies and smart metering devices" ,Intelligent Data Acquisition and Advanced Computing Systems (IDAACS), 2011 IEEE 6th International Conference on, On page(s): 812 816Volume: 2, 15-17 Sept. 2011

[2] SaiKiranEllenki, Srikanth Reddy G and Srikanth Ch.," An Advanced Smart Energy Metering System for Developing Countries" International Journal Of Scientific Research And Education, Volume 2 Issue 1 Pages 242-258 2014 ISSN (e): 23217545

[3] Mohammad Rezaul Islam and HasibIqbalMamun,"Energy Understanding Device (EUD): An Innovative Energy Metering and Monitoring Solution", Journal of Modern Science and Technology, Vol. 3. No. 1. March 2015 Issue. Pp.47-63

[4] Athira.P.M and D.JeslinJeniba," Electricity Theft Control Using Smart PrepaidEnergy Meter", International Journal on Applications in Electrical and Electronics Engineering, Volume 1: Issue 3: March 2015, pp 16-20.

[5] Dr. M. J. C. Prasad and YeligatiKiran, "Prepayment of Electricity Units with Theft Controlling System", International Journal of Research Studies in Science, Engineering and Technology [IJRSSET], Volume 1, Issue 4, July 2014, PP 42-48

[6] Gayathri.M and Harish.I, "Efficient Power Management In Home Using Wireless Sensor Networks", International Journal of Advanced Research in Electronics and Communication Engineering (IJARECE), Volume 3, Issue 12, December 2014.

[7] R. Ramalakshmi and G.Balaji, "Power Management in Home Area Network Using Zigbee Protocol", International Journal of Science and Research (IJSR), ISSN (Online): 2319-7064

[8] ParulRanjan, NamitaMehra, Prof. T.A. More and ShripadBokand, "Wireless Design for Power Theft Monitoring", International Journal of Computer Technology and Electronics Engineering (IJCTEE), Volume 2, Issue 2

[9] Wang Zhi Dong and Zhang Kedong., "Energy meter monitoring sensor network technology research", Electricity Distribution (CICED), 2010 China International Conference on, On page(s): 1-7, 13-16 Sept. 2010

[10] Selvapriya.C, "Competent Approach For Inspecting Electricity Theft", International Journal of Innovative Research in Science, Engineering and Technology, Volume 3, Special Issue 3, March 2014

[11] Ling LUO, Kaiyan XIAO, Zhiyong CHEN and Jiapei JIN, "DEFENDING ELECTRICITY-STEALING BASED ON DATA ANALYSIS: A NOVEL APPLICATION OF ADVANCED METERING INFRASTRUCTURE FOR DISTRIBUTION NETWORKS", CIRED Workshop - Rome, 11-12 June 2014 Paper0192

[12] Satish, RaghulAsokan, SrinivasBharathwaj and Sujaudeen N, "Automated Meter Reading System", International Journal of Computer Applications (0975 - 8887), Volume 116 - No. 18, April 2015

[13] SANUKRISHNANS.B, "A COGNITIVE ENERGY DISTRIBUTION SYSTEM", International Journal of Peer to Peer 
Networks (IJP2P) Vol.5, No.2, May 2014

[14] E.MoniSilviya, K.MeenaVinodhini and SalaiThillaiThilagam.J, "GSM Based Automatic Energy Meter System with Instant Billing", International Journal of Advanced Research in Electrical, Electronics and Instrumentation Engineering, Vol. 3, Special Issue 3, April 2014

[15] Andrew Sloss, Dominic Symes and Chris Wright, ARM System Developer's Guide: Designing and Optimizing System Software, 1st Edition, Morgan Kaufmann, USA, 2004

[16] Steve Furber, ARM System-on-Chip Architecture, 2nd Edition, Addison-Wesley Professional, 2000

[17] http://www.arm.com/products/processors/cortex-m/index.php

[18] http://www.engineersgarage.com/articles/arm-advanced-riscmachines-processors

[19] http://www.st.com/web/en/catalog/mmc/FM141/SC1169/SS1577/L N11/PF252140

[20] http://stm32f4-discovery.com/2014/05/all-stm32f429-libraries-atone-place/

[21] https://www.iar.com/iar-embedded-workbench/arm/

[22] http://webstaff.itn.liu.se/ qinye/tne090/EW_GettingStarted.ENU.pd $\mathrm{f}$

[23] https://www.youtube.com/watch?v=mDxn-wdixoM

[24] https://www.youtube.com/watch?v=-C2MjbJXAyw 